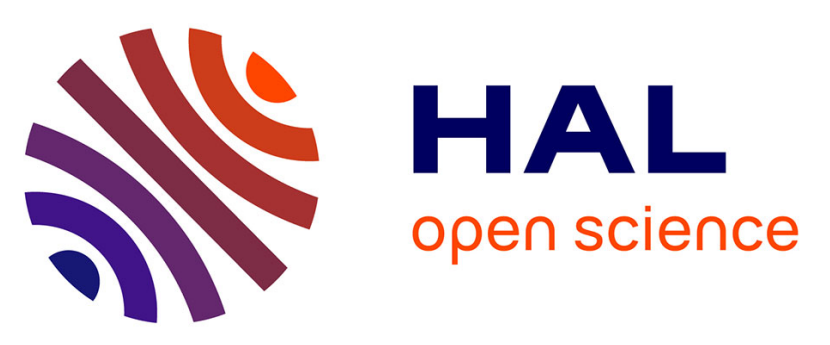

\title{
A viscoelastoplastic stiffening model for plant fibre unidirectional reinforced composite behaviour under monotonic and cyclic tensile loading
}

Fabrice Richard, Christophe Poilâne, Haomiao Yang, Florian Gehring, Emile Renner

\section{To cite this version:}

Fabrice Richard, Christophe Poilâne, Haomiao Yang, Florian Gehring, Emile Renner. A viscoelastoplastic stiffening model for plant fibre unidirectional reinforced composite behaviour under monotonic and cyclic tensile loading. Composites Science and Technology, 2018, 167, pp.396 - 403 . hal-02130045

\section{HAL Id: hal-02130045 \\ https://hal.science/hal-02130045}

Submitted on 15 May 2019

HAL is a multi-disciplinary open access archive for the deposit and dissemination of scientific research documents, whether they are published or not. The documents may come from teaching and research institutions in France or abroad, or from public or private research centers.
L'archive ouverte pluridisciplinaire $\mathbf{H A L}$, est destinée au dépôt et à la diffusion de documents scientifiques de niveau recherche, publiés ou non, émanant des établissements d'enseignement et de recherche français ou étrangers, des laboratoires publics ou privés. 


\section{A viscoelastoplastic stiffening model for plant fibre unidirectional reinforced composite behaviour under monotonic and cyclic tensile loading} F. Richarda ${ }^{*}$, C. Poilâne $e^{b, c, d, e}$, H. Yangb,c,d,e, F. Gehringb,c,d,e, E. Rennera

a Univ. Bourgogne Franche-Comté, Institut FEMTO-ST, CNRS/UFC/ENSMM/UTBM

*Département Mécanique Appliquée, 24 rue de l’Epitaphe, F-25000 Besançon, France fabrice.richard@univ-fcomte.fr

emile.renner@gmail.com

b Normandie Univ., France

c UNICAEN, CIMAP, F-14050 Caen, France

d ENSICAEN, F-14050 Caen, France

e CNRS, UMR 6252, F-14050 Caen, France

christophe.poilane@unicaen.fr

haomiao.yang@unicaen.fr

florian.gehring@unicaen.fr

Keywords: flax; viscoelasticity; viscoplasticity; stiffening; phenomenological modelling 


\section{Abstract}

At room conditions and standard strain rate $\left(\dot{\varepsilon} \sim 10^{-4} \mathrm{~s}^{-1}\right)$, unidirectional (UD) plantbased reinforced organic polymers often exhibit nonlinear mechanical behaviour in tension. A viscoelastoplastic model (VEP model) for the simulation of UD plant fibre composite mechanical behaviour in tension, previously validated from twisted flax yarn epoxy composite under room conditions and standard strain rate, is calibrated with new data obtained from flax fibre epoxy composite under repeated progressive loading and a wide range of strain rates $\left(\dot{\varepsilon} \sim 10^{-3}\right.$ to $\left.10^{-7} \mathrm{~s}^{-1}\right)$. The VEP model does not reproduce well the experimental observations. There seems to be a lack of stiffening in this phenomenological model.

We propose an improved VEP model, developed within the frameworks of thermodynamics and limited to uniaxial tension and infinitesimal strains. An internal variable $s$ representing the stiffening is added to create a VEP-stiffening model. This internal variable represents the coupled effects of reorienting cellulose microfibrils in kink band areas, spiral spring-like extension of cellulose microfibrils, and shear-stressinduced crystallization of the amorphous cellulose of flax fibres. The stiffening phenomenon was considered viscous, without a threshold, and was related to the tension energy in the direction of the fibres. Three viscosity coefficients drive the three phenomena: $\eta$ (elastic), $K$ (plastic), and $K_{S}$ (stiffening). In the chosen formalism, this leads to two thermodynamic potentials $\varphi_{V E P S}$ and $\Omega_{V E P S}$ in which the stiffening phenomenon is strongly coupled with all the others.

This VEP-stiffening model of the UD flax fibre epoxy composite correlates well with experimental observations. The paper also explores the evolution of the three viscous 
phenomena (elastic, plastic, and stiffening) by simulation of different loading conditions: monotonic, cyclic, and creep.

This VEP-stiffening model can easily enrich existing multiaxial models of UD behaviour in the fibre direction. Implemented in a finite element model, it could be used at different length scales to numerically explore the origin of the mechanical behaviour of plant-based reinforced polymers. 


\section{Introduction}

Plant-based reinforced polymer often presents nonlinear mechanical behaviour. This becomes particularly evident for tensile loading in the fibre direction, with the presence of an apparent yield point that separates the tensile curve into two regions. This phenomenon has been observed for flax fibre composites [1-5], unidirectional reinforcement $[1,6]$, random mat reinforcement $[1,7,6]$, and fibre composites other than those based on the flax plant $[6,8]$. The apparent yield point occurs at a very low level of strain, between $0.1 \%$ and $0.3 \%$, according to experimental conditions and measurement methods $[2,9]$. Sometimes-under a low loading rate, high temperature, or high specimen moisture (see Figure 3 in [3]) —an inflection point is observed in the tensile curve, even under infinitesimals strains. The region of the stress-strain curve after this inflection point is often called the '3rd region' in the field of green composites (Figure 1). A stiffening phenomenon, associated with reorientation of cellulose microfibrils in kink band areas, spiral spring-like extension of cellulose microfibrils, and shear-stress-induced crystallization of the amorphous cellulose of the flax fibres, could explain this third region [10]. 


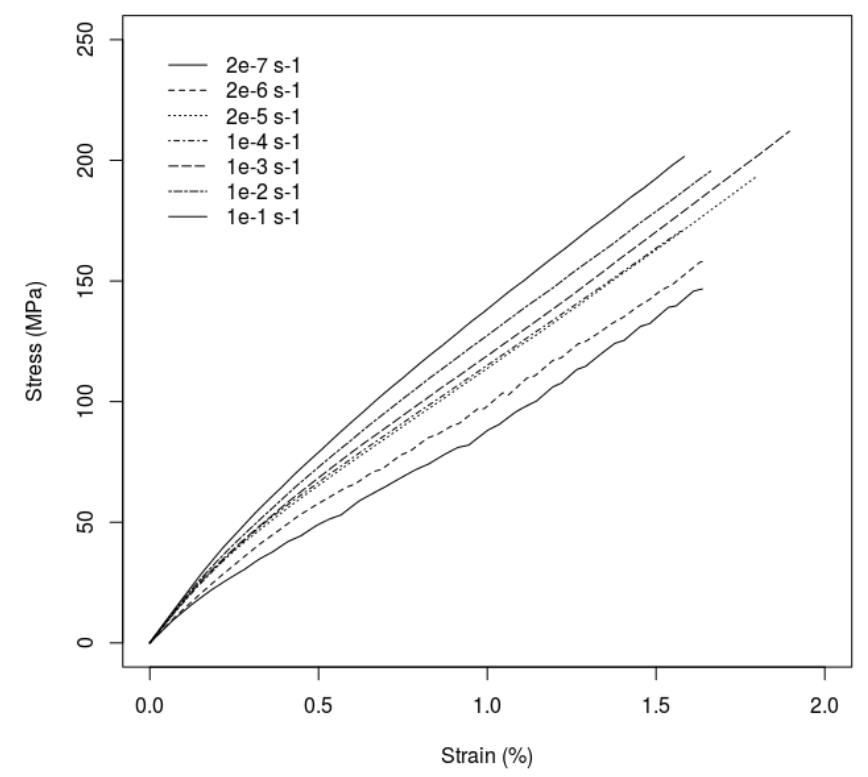

Figure 1 : Typical stress-strain curves obtained in tensile test at room temperature for seven loading rates (from [4]). An inflection point is observed at low loading rates.

Some authors have developed models to simulate the nonlinear mechanical behaviour of natural fibre-based composites [11,12,8,13-16]. For instance, Marklund et al. proposed using the Schapery framework theory to develop a viscoelastic-viscoplastic model including stiffness degradation for hemp/lignin composites [15]. The Schapery theory coupled with the Boltzman superposition principle was used by Kontou et al. [16] to model nonlinear viscoelasticity-viscoplasticity of bio-based polymer composites. In a previous work [4], we proposed a phenomenological viscoelastoplastic model (VEP model) to study the nonlinear effects of viscoelastic and viscoplastic phenomena in plant fibre composites. This VEP model simulates the uniaxial monotonic and cyclic behaviour of quasi-unidirectional twisted flax-yarn-reinforced epoxy composites at strain rate $\dot{\varepsilon} \sim 10^{-4} \mathrm{~s}^{-1}$ and normal conditions (room temperature, normal humidity). This VEP model integrates viscoelastic and viscoplastic contributions, but no stiffening. This model is therefore unable to simulate low-speed tests when a third region is observed. Although all the above-mentioned works succeeded in describing some aspects of nonlinearity, 
none were used to describe the apparent increase of rigidity observed in bio-based composites.

The main purpose of this paper is to improve the VEP model by adding this stiffening phenomenon. In this study, the used material is a unidirectional flax-reinforced epoxy composite, and the loading strain rate range is wide enough $\left(\dot{\varepsilon} \sim 10^{-3}\right.$ to $\left.10^{-7} \mathrm{~s}^{-1}\right)$ to explore the phenomenon of stiffening in repeated progressive loading (RPL). This VEPstiffening model can be a valuable aid to the understanding of plant-fibre-reinforced composite behaviour at different scales-for example, to understand what happens to the composites in the third region of the tensile curve at low loading rate [4], high temperature, or high specimen moisture [3]. 


\section{Materials and Methods}

\subsection{UD specimens and mechanical testing procedure}

Flax fibre reinforcement originates from the flax stem. After harvesting, the fibres are treated according to the usual steps: retting, scutching, hackling, and combined folding/drawing. With $n$ iterations of folding/drawing, the flax fibres are subjected to refining, which involves stretching the technical fibres to form ribbons. The flax ribbons are then manufactured by one more step just after folding/drawing: a widening/flattening process. In that step, several strands are connected in parallel with the help of pulverised water to soften the natural pectins and use them as glue between the fibres [17]. The output is a purely UD ply of flax (FlaxTape, Lineo-Flax Fiber Impregnation) [18]. We considered this product of UD flax fibres as non-pretreated reinforcement, for which flax did not undergo any particular selection process by the manufacturer. We also applied no treatment. The flax reinforcement used in this work weighed $110{\mathrm{~g} . \mathrm{m}^{-2}}^{-2}$ (values from the manufacturer). The properties of plant fibres are affected by many factors including variety, climate, harvest, maturity, retting degree, decortication, mechanical disintegration, fibre modification, and textile and technical processes [12]. The matter was supplied without any information concerning variety and growing conditions. However, because the technical flax fibres were obtained from the same manufacturer, it may be assumed that the fibres were grown under similar environmental conditions. In this way, the impact of environmental factors could be considered reduced while retaining the same technical processes. Generally, the number of plies is selected according to the desired architecture and composite component fraction. In this study, ten plies of UD at $0^{\circ}$ were always used to manufacture the required 
composite laminates. This choice was selected to obtain a relatively high volume fraction of UD flax reinforcement $\left(V_{f}=47 \%\right)$, which reduced the variability of the local fibre orientations. The mechanical properties of elementary flax fibres were as follows: Young's modulus between $27 \mathrm{GPa}$ and $80 \mathrm{GPa}$, ultimate stress between $345 \mathrm{MPa}$ and $1830 \mathrm{MPa}$, and ultimate elongation between $1.2 \%$ and $3.2 \%[19,20]$. The resin used in this study was a standard Huntsman industrial resin for laminating, with low viscosity and high flexibility. This warm-curing epoxy system was based on Araldite LY1564SP associated with a polyamine accelerator hardener XB3486. The mechanical properties given by the producer were as follows: Young's modulus between $28.6 \mathrm{GPa}$ and $30 \mathrm{GPa}$, tensile strength between $70 \mathrm{MPa}$ and $74 \mathrm{MPa}$, and elongation at tensile strength between $4.6 \%$ and 5.0\%. The composite plates were developed using a liquid composite moulding with the hot platen press method described in [4]. The curing process was carried out in conformity with one of the manufacturer's instructions ( $8 \mathrm{~h}$ at $\left.80{ }^{\circ} \mathrm{C}\right)$. We chose $80{ }^{\circ} \mathrm{C}$ as the curing temperature to reduce both the thermal impact on the mechanical properties of the fibres [21] and the effect of the expansion coefficient of the aluminium mould on the surface conditions of the composite. Two flax composite laminates with dimensions of $(330 \times 250 \times 1.67) \mathrm{mm}^{3}$ were used for the present work. The reinforcement inside the final composite plates was constituted by a mixture of elementary fibres and bundles of fibre (bundles as existing in a flax stem). Consequently, this reinforcement was mainly oriented in the longitudinal direction of the composite, which was the optimal organisation to analyse the mechanical behaviour. Particularly, we believe this type of plant fibre composite (high performance, unidirectional, limited reinforcement variability, linear behaviour matrix) offers the best conditions to analyse the third region of tensile curves introduced previously. 
UD specimens (width $15 \mathrm{~mm}$, length $250 \mathrm{~mm}$ ) were tested under RPL in tension at $20{ }^{\circ} \mathrm{C}$ using an Instron hydraulic machine equipped with a 100-kN load cell. A strain gauge was glued to each tested specimen (Vishay 125LT Tee Rosette) to accurately measure the strain. Specimens were subjected to successively larger loading-unloading cycles (cf. Figure 2) at a constant load/unload stress rate. Four load/unload stress rates were used: 0.01, $0.1,1$ and $10 \mathrm{MPa}^{-1} \mathrm{~s}^{-1}$ (test duration: 1650, 167, 24 and $4 \mathrm{~min}$, respectively). This important range made it possible to explore the potential viscous phenomena of stiffening and couplings in the strain rate range corresponding to $10^{-3}$ to $10^{-7} \mathrm{~s}^{-1}$.

\subsection{Thermodynamic framework for modelling}

In a previous work [4], a VEP model was proposed to study the nonlinear effects of unidirectional flax-reinforced epoxy composite. This VEP model provides an accurate prediction of the uniaxial mechanical response (RPL, creep, and relaxation) of UD twisted flax yarn reinforced epoxy composite at strain rate $\dot{\varepsilon} \sim 10^{-4} \mathrm{~s}^{-1}$ and normal conditions: room temperature and usual humidity. This VEP model is based on a behaviour model developed for unidirectional glass-fibre-reinforced epoxy composite [22] by considering a linear viscoelastic part, modified nonlinear hardening, and no damage. The total strain $\varepsilon$ is partitioned into an elastic part $\varepsilon^{e}$ (instantaneous reversible) and an inelastic part $\varepsilon^{i n}$ (non-instantaneous reversible), which is the sum of anelastic contribution $\varepsilon^{\text {an }}$ (timedependent reversible, due to delayed elasticity) and viscoplastic contribution $\varepsilon^{v p}$ (timedependent irreversible, sometimes qualified as creep strain). The sum of the elastic and anelastic parts is also called the viscoelastic part $\left(\varepsilon^{v e}=\varepsilon^{e}+\varepsilon^{a n}\right)$ :

$$
\varepsilon=\varepsilon^{e}+\varepsilon^{i n}=\varepsilon^{e}+\varepsilon^{a n}+\varepsilon^{v p}=\varepsilon^{v e}+\varepsilon^{v p}
$$

In the context of thermodynamics with internal variables [23], physical phenomena can be described with a precision that depends on the choice of state variables. According to this approach, it is assumed that in a homogeneous continuous medium equivalent to the 
real material, the microscopic physical phenomena are represented by means of macroscopic internal variables. The state variables are the observable variables (total strain $\varepsilon$ ) and the internal variables $\left(\varepsilon^{e}, \alpha_{i}, \ldots\right)$. The standardized framework [24] assumes that mechanical behaviour is obtained when two potentials are defined: a free energy density $\psi\left(\varepsilon^{e}, \alpha_{i}, \ldots\right)$ to define state laws and a dissipation potential $\Omega$, which depends on the associated variables (Cauchy's stress $\sigma, X_{i}, \ldots$ ), to determine the evolution of internal variables. Based on the experimental results, the free energy and dissipation potential are proposed, and the state laws can then be written as

$$
\begin{aligned}
& \sigma=\rho \frac{\partial \psi}{\partial \varepsilon^{e}} \\
& X_{i}=\rho \frac{\partial \psi}{\partial \alpha_{i}}
\end{aligned}
$$

where $\rho$ is the mass density. The evolution of internal variables is expressed as

$$
\begin{aligned}
& \dot{\varepsilon}^{i n}=\frac{\partial \Omega}{\partial \sigma} \\
& \dot{\alpha}_{i}=-\frac{\partial \Omega}{\partial X_{i}}
\end{aligned}
$$

For the automatic satisfaction of the second principle of thermodynamics, these two potentials must possess certain properties: nonnegativity, convexity, and zero at the origin [23]. The system of ordinary differential equations was solved using MIC2M software [25] via an explicit Runge-Kutta formula [26].

\subsection{Model calibration method}

An inverse method approach was used to extract the constitutive parameters from the experimental strain measurements during the RPL tests. This approach consists of an optimisation problem, the objective of which is to minimise function $V$ :

$$
\widehat{\boldsymbol{\theta}}=\underset{\boldsymbol{\theta} \in \boldsymbol{\Theta}}{\operatorname{argmin}} V(\boldsymbol{\theta})
$$


where vector $\boldsymbol{\theta}=\left(\theta_{1}, \ldots, \theta_{n}\right)$ is the vector of the unknown parameters, and $V$ is the cost function-i.e., the gap between the experimental strain $\varepsilon_{m}$ (m "measured") and the numerical results $\varepsilon_{c}$ ( $c$ "calculated"), which can be defined as

$$
V(\boldsymbol{\theta})=\frac{1}{4} \sum_{o=1}^{4}\left[\frac{1}{N^{(o)} \varepsilon_{\max }^{(o)}} \sum_{i=1}^{N^{(o)}}\left[\varepsilon_{c}^{(o)}\left(\boldsymbol{\theta}, t_{i}^{(o)}\right)-\varepsilon_{m}^{(o)}\left(t_{i}^{(o)}\right)\right]^{2}\right]
$$

In Eq. (7), subscript (o) indicates the number of the RPL test considered. The acquisition time $t_{i}^{(o)}$ corresponds to the $i^{t h}$ data point of the $o^{\text {th }}$ test. $N^{(o)}$ is the number of acquisition times, and $\varepsilon_{\max }^{(o)}$ is a weighting coefficient defined as the maximal strain value in the $o^{\text {th }}$ experimental RPL test. The minimization problem was solved using an algorithm based on the Levenberg-Marquardt method coupled with the genetic approach implemented in MIC2M [27,25].

To determine whether the richness of the data is suitable for reliable parameter estimation, an identifiability analysis was also performed $[28,4]$. This analysis was based on the local sensitivity functions of the numerical strain to the parameters. 


\section{Results and Discussion}

\subsection{Shortcomings of the VEP model}

In a previous work [4], a VEP model was proposed to study the nonlinear effects of unidirectional flax-reinforced epoxy composite. Based on experimental results, the free energy $\psi_{V E P}$ and dissipation potential $\Omega_{V E P}$ were proposed in the following equations [4]:

$$
\begin{aligned}
& \rho \psi_{V E P}=\frac{1}{2} E\left[\left(\varepsilon^{e}\right)^{2}+\sum_{i=1}^{3} \beta_{i} \alpha_{i}^{2}\right] \\
& \Omega_{V E P}=\frac{\left(\sigma-X_{1}\right)^{2}}{2 \eta}+\frac{\langle f\rangle^{2}}{2 K}
\end{aligned}
$$

with

$$
f=\left|\sigma-X_{2}-X_{3}\right|-\sigma_{Y}+\frac{\gamma_{3}}{2 E \beta_{3}} X_{3}^{2}
$$

The internal variables $\alpha_{i}$ (strain) and driving force $X_{i}$ (stress) represent inelastic phenomena: anelastic $(i=1)$ and viscoplastic $(i=2,3) . E$ and $\sigma_{Y}$ are Young's modulus (instantaneous elastic modulus) and the initial yield stress, respectively. $\eta$ and $K$ are viscosity coefficients corresponding to delayed elasticity (anelasticity) and delayed plasticity (viscoplasticity), respectively. Parameter $\beta_{1}$ is the anelastic rigidity ratio; $\beta_{2}, \beta_{3}$, and $\gamma_{3}$ are hardening parameters. The symbol \langle\rangle denotes Macauley's brackets such that $\langle x\rangle=0$ if $x<0$ and $\langle x\rangle=x$ if $x \geq 0$.

From a rheological point of view, the model proposed here is, for elastic contribution, a linear spring $E$ and, for anelastic contribution, a classical Kelvin-Voigt model which comprising a linear viscous damper $\eta$ and a linear spring $\left(E \beta_{1}\right)$ - with internal stress $X_{1}$ - 
connected in parallel. For viscoplastic contribution, a more complex model is required. It comprises a linear viscous damper $K$, a skidding block $\sigma_{Y}$ connected in parallel, and two additional kinematic hardenings with internal stresses $X_{2}$ and $X_{3}[29,30]$ : a linear $\left(E \beta_{2}\right)$ [31] and a nonlinear $\left(E \beta_{3}, \gamma_{3}\right)$ from Armstrong-Frederick [32]. In addition, a coupling between translation (kinematic hardening) and contraction (negative isotropic hardening) of the elastic domain is added through the last term of equation (10) [33].

The state laws can then be written as

$$
\begin{aligned}
& \sigma=\rho \frac{\partial \psi_{V E P}}{\partial \varepsilon^{e}}=E \varepsilon^{e} \\
& X_{i}=\rho \frac{\partial \psi_{V E P}}{\partial \alpha_{i}}=E \beta_{i} \alpha_{i}
\end{aligned}
$$

The evolution of internal variables is expressed as

$$
\begin{aligned}
& \dot{\varepsilon}^{i n}=\frac{\partial \Omega_{V E P}}{\partial \sigma}=\sum_{i=1}^{2} \dot{\alpha}_{i}=\dot{\varepsilon}^{a n}+\dot{\varepsilon}^{v p} \\
& \dot{\alpha}_{i}=-\frac{\partial \Omega_{V E P}}{\partial X_{i}}
\end{aligned}
$$

This VEP model is an eight-parameter model: $\left(\theta_{1}, \ldots, \theta_{8}\right)=\left(E, \eta, \beta_{1}, \sigma_{Y}, K, \beta_{2}, \beta_{3}, \gamma_{3}\right)$.

The result of this VEP model calibration using the four RPL tests $(0.01,0.1,1$ and $10 \mathrm{MPa} . \mathrm{s}^{-1}$ ) in equation (7) is presented in Table 1. Figure 2 shows simulated responses with parameters estimated by minimisation of the cost function $V$ defined by equation (7). 
Table 1 : Eight material parameters for UD flax/epoxy composite. VEP model [4]. Cost function value: $V(\widehat{\boldsymbol{\theta}})=3.0 \times 10^{-4}$

\begin{tabular}{llll}
\hline$i$ & Parameter $\theta_{i}$ & Definition & Estimation $\hat{\theta}_{i}$ \\
\hline 1 & $E$ (MPa) & Young's modulus & $3.22 \times 10^{4}$ \\
2 & $\eta$ (MPa.s) & elastic delayed (anelastic) viscosity & $1.71 \times 10^{6}$ \\
3 & $\beta_{1}$ & anelastic rigidity ratio & 2.55 \\
4 & $\sigma_{Y}$ (MPa) & initial yield stress & $1.62 \times 10^{1}$ \\
5 & $K$ (MPa.s) & plastic viscosity & $1.62 \times 10^{7}$ \\
6 & $\beta_{2}$ & linear kinematic hardening ratio & 1.12 \\
7 & $\beta_{3}$ & linear hardening ratio & 1.64 \\
8 & $\gamma_{3}$ & nonlinear hardening (recall) & $1.15 \times 10^{3}$ \\
\hline
\end{tabular}



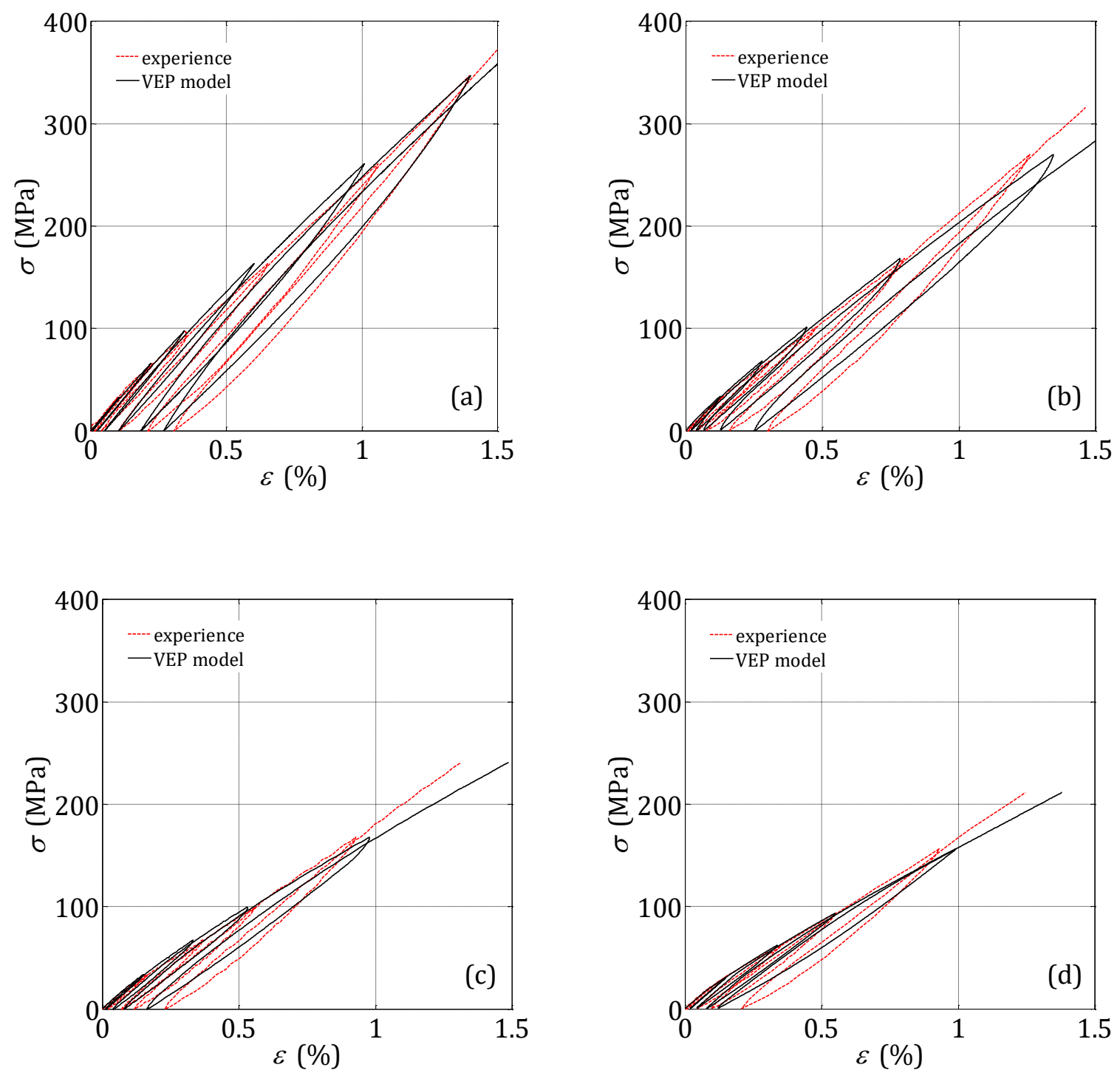

Figure 2 : Simulation response versus experimental data for progressive repeated loading at different load/unload rates using the VEP model.

(a) $10 \mathrm{MPa} . \mathrm{s}^{-1}$ (b) $1 \mathrm{MPa} . \mathrm{s}^{-1}$ (c) $0.1 \mathrm{MPa}^{-1} \mathrm{~s}^{-1}$ (d) $0.01 \mathrm{MPa}^{-1}$

It is clear that the viscoelastoplastic model does not correlate very well with the experimental data. The simulations are systematically lacking in stiffness. The increase in the apparent tangent modulus - visible from the fourth load in Figures 2d and 2c, from the fifth load in Figure 2b, and from the seventh load in Figure 2a-was impossible to simulate. No stiffening effect has been considered with our model for a strain above $0.5-$ $1 \%$ (depending on the load/unload rate). Consequent to this underestimation of stiffness, 
the apparent 'permanent' strains (at zero stress) predicted are lower than the experimental ones, loop after loop.

The VEP model can simulate the second region of the tensile stress-strain curve, but not the third observed in certain stress-strain curves for low strain rates. This third region corresponds to the portion in the stress-strain tensile curve after the inflection point observed in some favourable conditions (Figure 1).

\subsection{VEP-stiffening model}

In this section, the VEP model is improved to consider a stiffening phenomenon during loading. The idea of a stiffening phenomenon emerged because of the stronger assumptions researchers make in the case of bast-fibre-reinforced polymer: the possibility for microfibrils to reorient themselves during longitudinal loading (microfibril being the main component of bast fibres), even when fibres are trapped inside the matrix. The reorientation of microfibrils has been demonstrated experimentally on elementary fibre and bundles of fibres under tensile testing [34] and has been correlated to numerical results using a 3D finite element model [35]. The question of this reorientation when bast fibres are used as a reinforcement in the composite is thus highly logical. For long-plantfibre composites, in the case of reorientation during longitudinal loadingnotwithstanding the scale of the reinforcement (untwist at the microfibril scale, untwist at the yarn scale, in-plane reorientation at the ply scale)—-the tangent modulus must be increased.

Consequently, a stiffening phenomenon strongly coupled with the viscoelastic and viscoplastic phenomena must be added to the VEP model. There is almost nothing that macroscopically distinguishes a stiffened representative volume element (RVE) and a 'virgin' one. It therefore becomes necessary to imagine an internal variable representative of the modified state of matter and capable of representing the stiffening effect (coupled 
effects of reorienting cellulose microfibrils in kink band areas, spiral spring-like extension of cellulose microfibrils, and shear-stress-induced crystallization of the amorphous cellulose of flax fibres). There are several possibilities for this choice, depending on the school of thought and the type of stiffness measurement envisaged (microstructural, physical, mechanical). We have chosen a global mechanical measurement. The internal variable representing this measure and its associated thermodynamic force are denoted $s$ (s "stiffening") and $Y$, respectively. This internal variable $0 \leq s \leq s_{m}$ characterizes the stiffened state. $s=0$ corresponds to the 'virgin' state, and $s=s_{m}$ is a value that must be identified using experimental data and must correspond to the state of maximal stiffening (reorientation of microfibrils completed for example).

We use the concept of effective stress introduced by Rabotnov [36]. The internal variable is not $d$ (which leads to a decrease in stiffness) as in damage mechanics [36-38], but $s$ (which leads to an increase in stiffness). If $F$ is the applied tensile force on section $A$ of the 'virgin' RVE, $\sigma=F / A$ is the usual stress satisfying the equilibrium equation. In the presence of stiffening, the effective stress is $\widetilde{\sigma}=F / \widetilde{A}=\sigma /(1+s)$. We also assume that the deformation behaviour is affected only by stiffening in the form of effective stress: any deformation behaviour of a stiffened RVE is represented by the constitutive laws of the 'virgin' RVE in which the usual stress $\sigma$ is replaced by the effective stress $\widetilde{\sigma}$. For example, the tensile linear elastic law of a stiffened RVE is written as $\varepsilon^{e}=\tilde{\sigma} / E=\sigma /[E(1+s)]$, where $E$ is Young's modulus (instantaneous elastic modulus). It is also assumed that inelasticity is affected in the same way (Figure 3). 


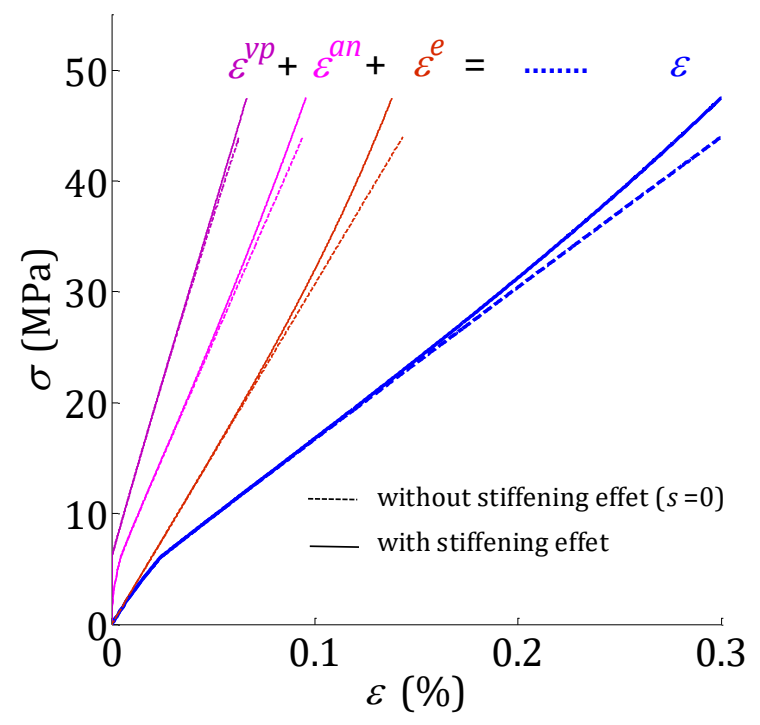

Figure 3 : Schematic representation of the effect of stiffening on elastic $\left(\varepsilon^{e}\right)$ and inelastic strains (anelastic $\varepsilon^{a n}$ and viscoplastic $\varepsilon^{v p}$ ) during a tensile test at $\dot{\varepsilon}=c^{\text {ste }}$.

In the proposed model, stiffening is activated from the beginning of loading (i.e., without a threshold) with a kinetic that depends on parameter $K_{S}$, which is the viscosity coefficient of the stiffening phenomenon. In the chosen formalism, this leads to two thermodynamic potentials $\varphi_{V E P S}$ and $\Omega_{V E P S}$ in which the stiffening phenomenon is strongly coupled with all the others:

$$
\begin{aligned}
& \rho \psi_{V E P s}=\frac{1}{2} E(1+s)\left[\left(\varepsilon^{e}\right)^{2}+\sum_{i=1}^{3} \beta_{i} \alpha_{i}^{2}\right] \\
& \Omega_{V E P s}=\frac{1}{2(1+s)^{2}}\left[\frac{\left(\sigma-X_{1}\right)^{2}}{\eta}+\frac{\langle f\rangle^{2}}{K}+\frac{Y^{2}}{K_{s}} \frac{\left\langle s_{m}-s\right\rangle}{s_{m}-s}\right]
\end{aligned}
$$

where $f$ is the same as in the VEP model and thus is given by

$$
f=\left|\sigma-X_{2}-X_{3}\right|-\sigma_{Y}+\frac{\gamma_{3}}{2 E \beta_{3}} X_{3}^{2}
$$

The state laws can then be written as

$$
\begin{aligned}
& \sigma=\rho \frac{\partial \psi_{V E P S}}{\partial \varepsilon^{e}}=E(1+s) \varepsilon^{e} \\
& X_{i}=\rho \frac{\partial \psi_{V E P S}}{\partial \alpha_{i}}=E(1+s) \beta_{i} \alpha_{i}
\end{aligned}
$$




$$
Y=\rho \frac{\partial \psi_{V E P S}}{\partial s}=\frac{1}{2} E\left[\left(\varepsilon^{e}\right)^{2}+\sum_{i=1}^{3} \beta_{i} \alpha_{i}^{2}\right]
$$

The evolution of internal variables is expressed as

$$
\begin{aligned}
& \dot{\varepsilon}^{i n}=\frac{\partial \Omega_{V E P S}}{\partial \sigma}=\sum_{i=1}^{2} \dot{\alpha}_{i}=\dot{\varepsilon}^{a n}+\dot{\varepsilon}^{v p} \\
& \dot{\alpha}_{1}=-\frac{\partial \Omega_{V E P S}}{\partial X_{1}}=\frac{\left(\sigma-X_{1}\right)}{\eta(1+s)^{2}} \\
& \dot{\alpha}_{2}=-\frac{\partial \Omega_{V E P s}}{\partial X_{2}}=\frac{\langle f\rangle}{K(1+s)^{2}} \operatorname{sign}\left(\sigma-X_{2}-X_{3}\right) \\
& \dot{\alpha}_{3}=-\frac{\partial \Omega_{V E P s}}{\partial X_{3}}=\dot{\alpha}_{2}-\frac{\langle f\rangle}{K(1+s)^{2}} \frac{\gamma_{3}}{\beta_{3} E} X_{3} \\
& \dot{s}=-\frac{\partial \Omega_{V E P s}}{\partial Y}=\frac{Y}{K_{s}(1+s)^{2}} \frac{\left\langle s_{m}-s\right\rangle}{s_{m}-s}
\end{aligned}
$$

This VEP-stiffening model (VEPs) is a ten-parameter model: $\left(\theta_{1}, \ldots, \theta_{10}\right)=$ $\left(E, \eta, \beta_{1}, \sigma_{Y}, K, \beta_{2,} \beta_{3}, \gamma_{3}, K_{s}, s_{m}\right)$. Three viscosity coefficients drive the three phenomena: $\eta$ (elastic), $K$ (plastic), and $K_{s}$ (stiffening).

The strong coupling between the phenomena requires a numerical calibration based on the inverse method (cf. $\S 2.3$ ). For the first approach, it can be assumed that $\beta_{1}=\beta_{2}=$ $\beta_{3}=1$ (rigidity equal to $E$ for anelastic and plastic phenomena) and $\gamma_{3}=0$ (nonlinear and isotropic hardening removed). This provides the first idea regarding the amplitude of all phenomena while keeping a simple 6-parameter model $\left(E, \eta, \sigma_{Y}, K, K_{s}, s_{m}\right)$ and a relevant starting point for the model calibration method explained in $§ 2.3$. Figure 4 shows the best fits obtained for the ten-parameter model, and the estimated parameter values are listed in Table 2 . The properties that these two potentials $\varphi_{V E P S}$ and $\Omega_{V E P S}$ must possess for the automatic satisfaction of the second principle of thermodynamics have been checked: nonnegativity, convexity, and zero at the origin [23]. 
Table 2 : Material parameters of the VEP-stiffening model. Cost function value: $V(\widehat{\boldsymbol{\theta}})=1.5 \times 10^{-4}$

\begin{tabular}{llll}
\hline$i$ & Parameter $\theta_{i}$ & Definition & Estimated value $\hat{\theta}_{i}$ \\
\hline 1 & $E$ (MPa) & Young's modulus & $3.07 \times 10^{4}$ \\
2 & $\eta$ (MPa.s) & elastic delayed (anelastic) viscosity & $1.37 \times 10^{8}$ \\
3 & $\beta_{1}$ & anelastic rigidity ratio & 1.37 \\
4 & $\sigma_{Y}(\mathrm{MPa})$ & initial yield stress & $6.00 \times 10^{0}$ \\
5 & $K_{(\mathrm{MPa} . s)}$ & plastic viscosity & $2.18 \times 10^{6}$ \\
6 & $\beta_{2}$ & linear kinematic hardening ratio & 1.28 \\
7 & $\beta_{3}$ & linear hardening ratio & 0.85 \\
8 & $\gamma_{3}$ & nonlinear hardening (recall) & $3.48 \times 10^{2}$ \\
\hline 9 & $K_{s}(\mathrm{MPa} . \mathrm{s})$ & stiffening viscosity & $4.57 \times 10^{3}$ \\
\hline 10 & $s_{m}(\%)$ & maximal stiffening & 22.3 \\
\hline
\end{tabular}



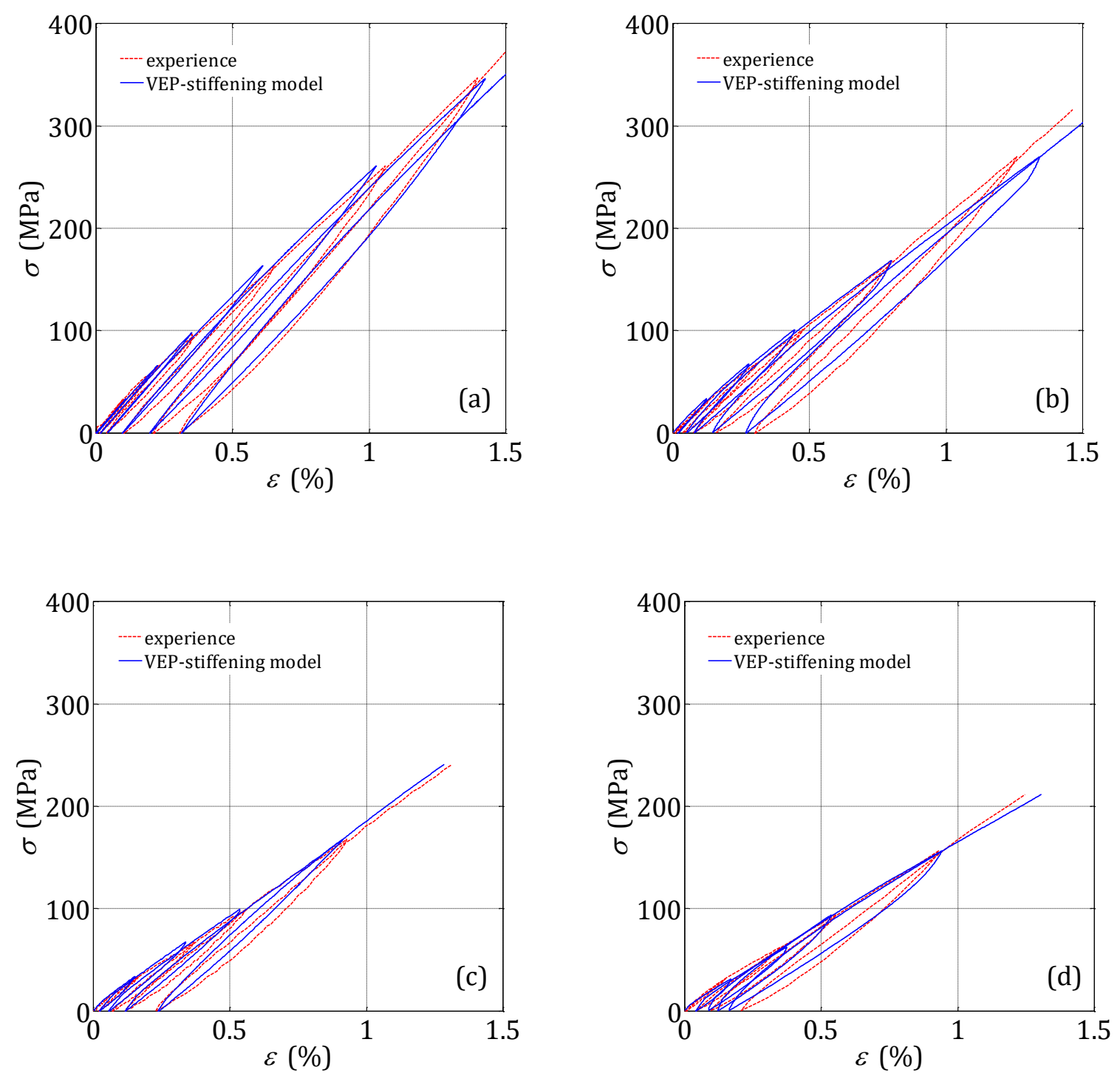

Figure 4 : Simulation response versus experimental data for progressive repeated loading at different load/unload rates using the VEP-stiffening model.

(a) $10 \mathrm{MPa}^{-1}$ (b) $1 \mathrm{MPa} \cdot \mathrm{s}^{-1}$ (c) $0.1 \mathrm{MPa} \cdot \mathrm{s}^{-1}$ (d) $0.01 \mathrm{MPa} \cdot \mathrm{s}^{-1}$

Note that the value of the cost function representing the model-experience gap is half that of the VEP model. The increase in the apparent tangent modulus-visible on the fourth and fifth loads-is clearly better predicted than previously. The apparent permanent strains at zero stress are also predicted. Figure 5 shows the difference between the two models for the RPL test at $0.1 \mathrm{MPa} . \mathrm{s}^{-1}$. In this test, the maximal stiffness $s_{m}$ is reached during the last load (Figure 7b). 


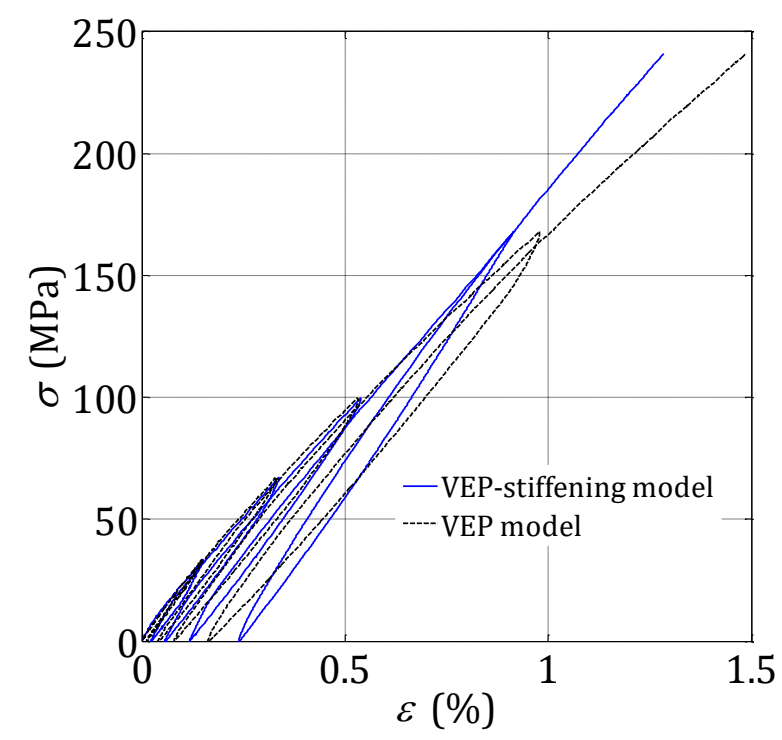

Figure 5 : Simulations of the RPL test at $0.1 \mathrm{MPa} . \mathrm{s}^{-1}$. VEP model versus VEP-stiffening model.

Figure 6 shows the evolution of the different strains (total, elastic, anelastic, and viscoplastic) during the highest and lowest loading rates. In the test at the highest speed, the anelastic strain is negligible, and the viscoplastic strain has only a short time to increase. In the tests with the lowest loading rate, elastic, anelastic, and viscoplastic strains are of the same order of magnitude. It can be noted that the 'elastic modulus' increases with each cycle and that this increase is more important for the lowest loading rate.
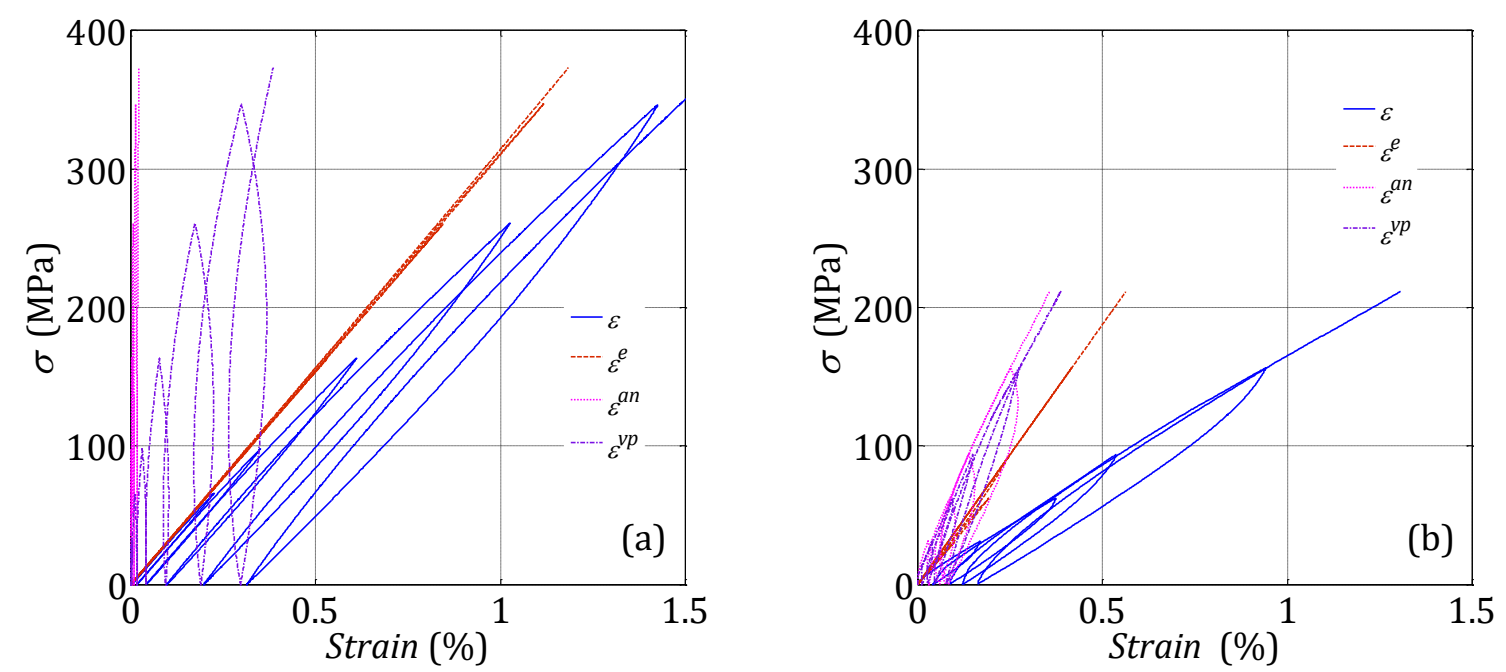

Figure 6 : Strain evolution during RPL tests for highest (a) $10 \mathrm{MPa} \cdot \mathrm{s}^{-1}$ and lowest (b) $0.01 \mathrm{MPa} . \mathrm{s}^{-1}$ loading rates. 
The VEP-stiffening model allows access to the evolution of stiffness during the tests, quantified by the internal variable $s$. Figure 7 shows the evolution of this internal variable $s$ during the four RPL tests.
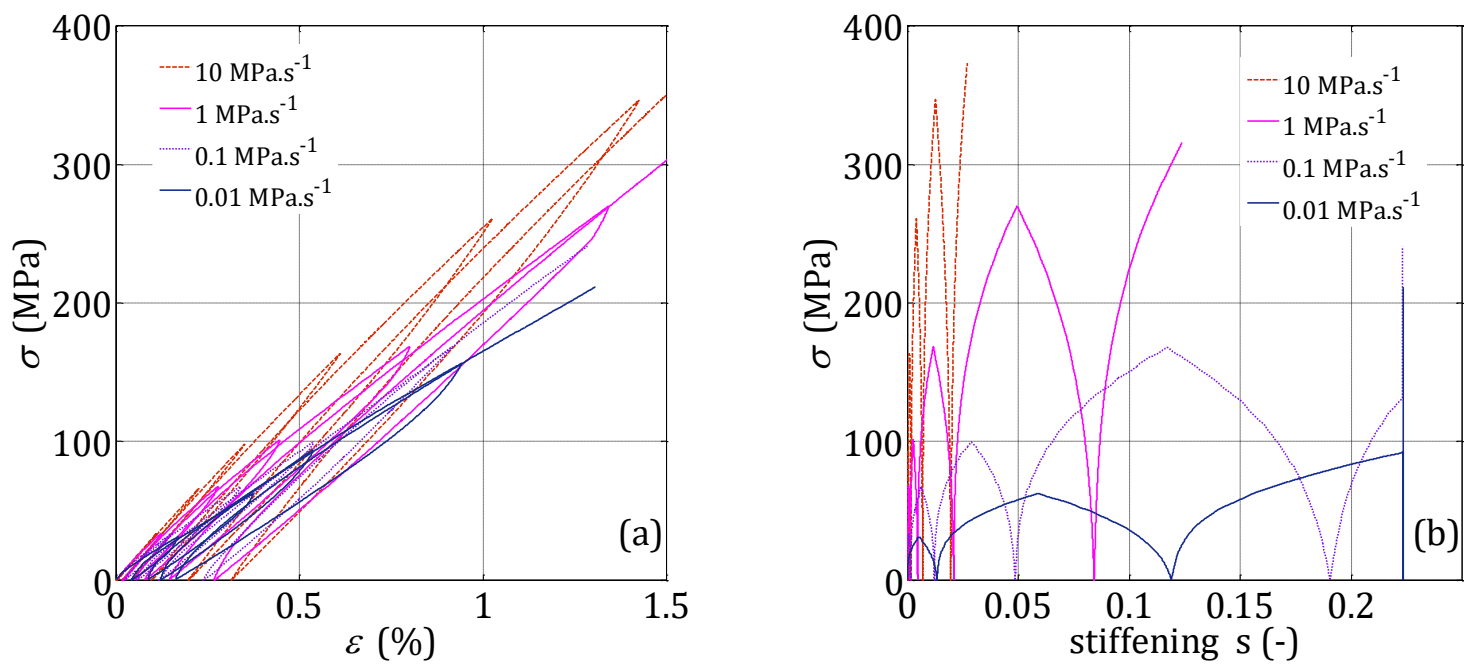

Figure 7 : (a) Stress-strain and (b) stiffening during RPL tests.

It can be seen in Figure 7 that only two low loading rates $\left(0.1 \mathrm{MPa} . \mathrm{s}^{-1}\right.$ and $\left.0.01 \mathrm{MPa} . \mathrm{s}^{-1}\right)$ allow the maximal value of the stiffening to be reached: $s_{m}=22.3 \%$. The higher the rate of loading, the lower the stiffening phenomenon. For the highest loading rate, despite the higher stresses, the stiffening obtained is only $2.7 \%$.

\subsection{Some stiffening effects}

The VEP-stiffening model can be a valuable aid to the understanding the plant-fibrereinforced composite behaviour at different scales. To improve the understanding of the model and the couplings involved in mechanical testing, we explore the evolution of the three viscous phenomena (elastic, plastic, and stiffening) by simulation using VEPstiffening for different loading conditions: monotonic and creep-recovery.

As shown in Figure 8, simulation of the monotonic tensile loading test at $\dot{\varepsilon}=10^{-5} \mathrm{~s}^{-1}$ with the VEP and VEP-stiffening models offers the possibility to observe the third apparent 
region. Note that the transition point from the second to the third approximately coincides with a stiffening value of $1 \%$.

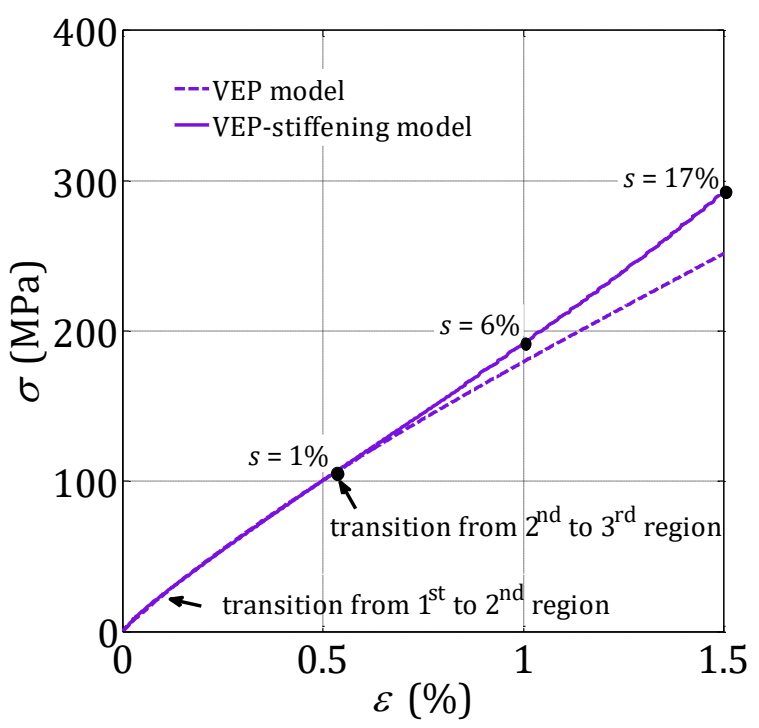

Figure 8 : Simulation of tensile test at $\dot{\varepsilon}=10^{-5} \mathrm{~s}^{-1}$ and evolution of the stiffening variable. Three regions of the stress-strain curve obtained with the VEP-stiffening model.

As shown in Figure 9, simulation of the creep-recovery tensile loading test at $\sigma_{0}=$ $200 \mathrm{MPa}$ with the two models offers the possibility to observe the decrease of the elastic strain during creep, here equal to $17 \%$. Owing to the viscosity of the phenomenon, the stiffening continues to increase slightly during the recovery phase $(+2 \%)$. It should be noted that the VEP-stiffening model is less sensitive to creep (at $200 \mathrm{MPa}$ ) and that stiffening here has a locking effect on the anelastic strain. 

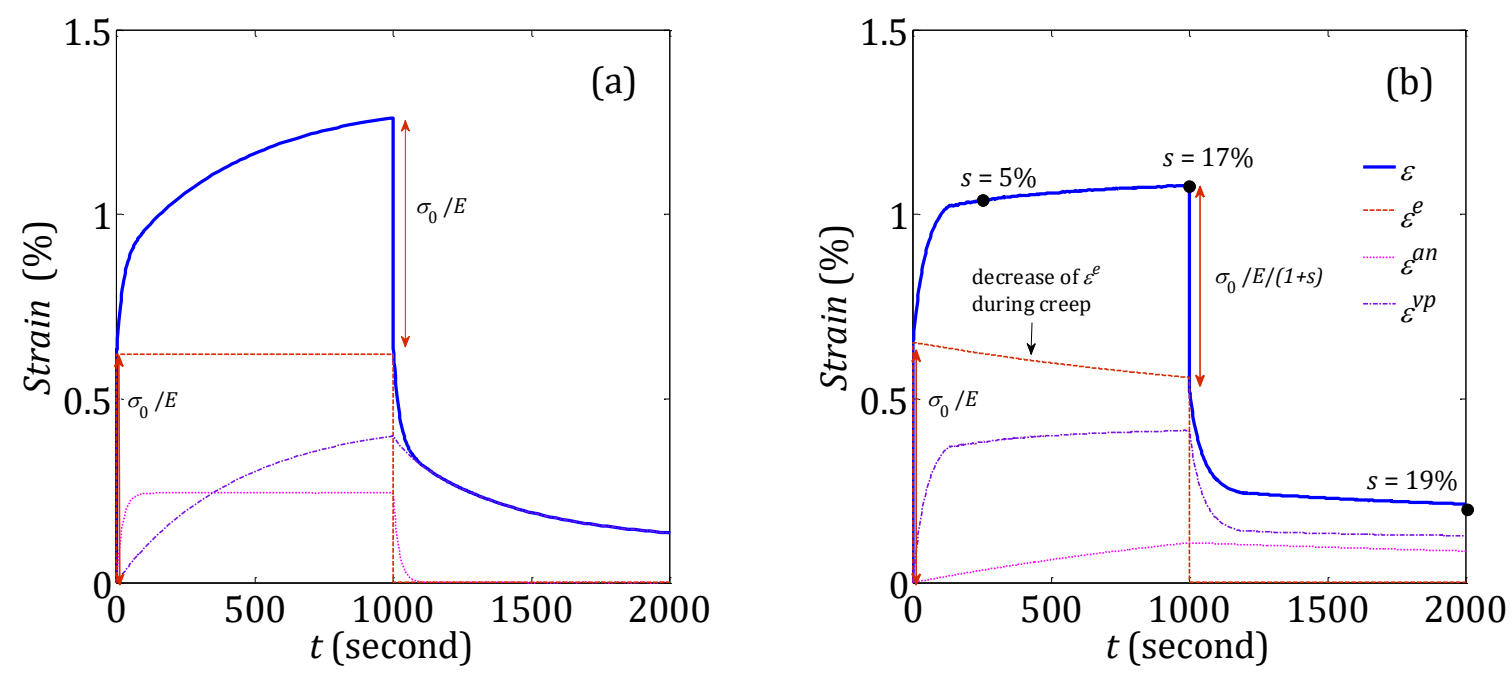

Figure 9 : Simulation of creep-recovery test at $\sigma_{0}=200 \mathrm{MPa}$ using the (a) VEP model and (b) VEP-stiffening model. We have already observed this locking effect experimentally in our previous work [4]. Our experimental observations (see Figure 11a,[4]) show that at this stress level, the stationary creep stage is obtained very quickly (approximately $2 \mathrm{~min}$ ) as provided by the VEP-stiffening model. The VEP model identified from RPL tests does not predict this stationarity and greatly overestimates the creep flow. 


\section{Conclusions}

We showed that apparent cyclic stiffening in tensile loading is impossible to simulate with our previous VEP model [4]. A low strain rate in tensile loading activated a stiffening phenomenon.

We proposed an improved VEP model, developed within the frameworks of thermodynamics, limited to uniaxial tension and infinitesimal strains (strain never exceeds $1.5 \%$ during tests). An internal variable $s$ (stiffening) was added to create a VEPstiffening model. This internal variable represented the coupled effects of cellulose microfibril reorientation in kink band areas, spiral spring-like extension of cellulose microfibrils, and shear-stress-induced crystallization of the amorphous cellulose in the flax fibres.

The stiffening phenomenon was considered viscous, without a threshold, and was related to the tension energy in the direction of the fibres ( $Y$ variable). In the VEP-stiffening model, three viscosity coefficients drove the three phenomena: elastic $(\eta)$, plastic $(K)$, and stiffening $\left(K_{S}\right)$. In the chosen formalism, this led to two thermodynamic potentials $\varphi_{V E P S}$ and $\Omega_{V E P S}$ in which the stiffening phenomenon was strongly coupled with all the others. This VEP-stiffening model of the UD flax fibre epoxy composite correlated well with experimental observations under repeated progressive loading in the strain rate range corresponding to $10^{-3}$ to $10^{-7} \mathrm{~s}^{-1}$. It also allowed us to simulate the third region, sometimes observed during monotonic tensile loading, and the decrease in the elastic strain during creep loading.

This model can easily enrich existing multiaxial models of UD behaviour in the fibre direction. Implemented in a finite element model, this VEP-stiffening behaviour could be 
used at different length scales to numerically explore the origin of the mechanical behaviour of plant-based reinforced polymers. A set of specific tests at different length scales under a wide range of temperatures and strain rates should help better understand the origins of stiffening. Particularly, it seems possible to measure the microfibril reorientation microfibrils with deformation using X-ray diffraction.

In addition to their features of density and environmental promise, UD flax fibre epoxy composite stiffens and plasticizes with different characteristic times. In addition, it can adapt its stiffness to the tensile energy provided in the direction of the fibres. This offers highly promising prospects regarding this category of composite materials. 


\section{Acknowledgement}

This research was supported by the French Ministry of Higher Education and Research and the China Scholarship Council. We thank Lineo NV for supplying the materials. 


\section{References}

[1] K. Oksman, High Quality Flax Fibre Composites Manufactured by the Resin Transfer Moulding Process, J. Reinf. Plast. Compos. 20 (2001) 621-627. doi:10.1177/073168401772678634.

[2] M. Hughes, J. Carpenter, C. Hill, Deformation and fracture behaviour of flax fibre reinforced thermosetting polymer matrix composites, J. Mater. Sci. 42 (2007) 2499-2511. doi:10.1007/s10853-006-1027-2.

[3] D. Scida, M. Assarar, C. Poilâne, R. Ayad, Influence of hygrothermal ageing on the damage mechanisms of flax-fibre reinforced epoxy composite, Compos. Part B Eng. 48 (2013) 51-58. doi:10.1016/j.compositesb.2012.12.010.

[4] C. Poilâne, Z.E. Cherif, F. Richard, A. Vivet, B. Ben Doudou, J. Chen, Polymer reinforced by flax fibres as a viscoelastoplastic material, Compos. Struct. 112 (2014) 100-112. doi:10.1016/j.compstruct.2014.01.043.

[5] L. Yan, N. Chouw, K. Jayaraman, Flax fibre and its composites - A review, Compos. Part B Eng. 56 (2014) 296-317. doi:10.1016/j.compositesb.2013.08.014.

[6] G. Lebrun, A. Couture, L. Laperrière, Tensile and impregnation behavior of unidirectional hemp/paper/epoxy and flax/paper/epoxy composites, Compos. Struct. 103 (2013) 151160. doi:10.1016/j.compstruct.2013.04.028.

[7] Z.E. Cherif, C. Poilâne, L. Moyamez, J. Chen, Optimisation d'un pré-imprégné lin/époxy industriel. Influence de l'orientation des fibres, Rev. Compos. Matér. Avancés. 21 (2011) 119-128. doi:10.3166/rcma.21.119-128.

[8] A. Rubio-López, T. Hoang, C. Santiuste, Constitutive model to predict the viscoplastic behaviour of natural fibres based composites, Compos. Struct. 155 (2016) 8-18. doi:10.1016/j.compstruct.2016.08.001.

[9] D.U. Shah, Damage in biocomposites: Stiffness evolution of aligned plant fibre composites during monotonic and cyclic fatigue loading, Compos. Part Appl. Sci. Manuf. 83 (2016) 160168. doi:10.1016/j.compositesa.2015.09.008.

[10] V. Placet, O. Cissé, M. Lamine Boubakar, Nonlinear tensile behaviour of elementary hemp fibres. Part I: Investigation of the possible origins using repeated progressive loading with in situ microscopic observations, Compos. Part Appl. Sci. Manuf. 56 (2014) 319-327. doi:10.1016/j.compositesa.2012.11.019.

[11] J. Andersons, J. Modniks, E. Sp rni, Modeling the nonlinear deformation of flax-fiberreinforced polymer matrix laminates in active loading, J. Reinf. Plast. Compos. 34 (2015) 248-256. doi:10.1177/0731684414568043.

[12] A. Chilali, W. Zouari, M. Assarar, H. Kebir, R. Ayad, Analysis of the mechanical behaviour of flax and glass fabrics-reinforced thermoplastic and thermoset resins, J. Reinf. Plast. Compos. 35 (2016) 1217-1232. doi:10.1177/0731684416645203.

[13] J. Sliseris, L. Yan, B. Kasal, Numerical modelling of flax short fibre reinforced and flax fibre fabric reinforced polymer composites, Compos. Part B Eng. 89 (2016) 143-154. doi:10.1016/j.compositesb.2015.11.038.

[14] Z. Mahboob, Y. Chemisky, F. Meraghni, H. Bougherara, Mesoscale modelling of tensile response and damage evolution in natural fibre reinforced laminates, Compos. Part B Eng. 119 (2017) 168-183. doi:10.1016/j.compositesb.2017.03.018.

[15] E. Marklund, J. Eitzenberger, J. Varna, Nonlinear viscoelastic viscoplastic material model including stiffness degradation for hemp/lignin composites, Compos. Sci. Technol. 68 (2008) 2156-2162. doi:10.1016/j.compscitech.2008.03.011.

[16] E. Kontou, G. Spathis, P. Georgiopoulos, Modeling of nonlinear viscoelasticity-viscoplasticity of bio-based polymer composites, Polym. Degrad. Stab. 110 (2014) 203-207. doi:10.1016/j.polymdegradstab.2014.09.001.

[17] M. Khalfallah, B. Abbès, F. Abbès, Y.Q. Guo, V. Marcel, A. Duval, F. Vanfleteren, F. Rousseau, Innovative flax tapes reinforced Acrodur biocomposites: A new alternative for automotive applications, Mater. Des. 64 (2014) 116-126. doi:10.1016/j.matdes.2014.07.029.

[18] Lineo - Flax Fiber Impregnation, (n.d.). http://www.lineo.eu/ (accessed January 24, 2016). 
[19] A. Bledzki, Composites reinforced with cellulose based fibres, Prog. Polym. Sci. 24 (1999) 221-274. doi:10.1016/S0079-6700(98)00018-5.

[20] K.L. Pickering, M.G.A. Efendy, T.M. Le, A review of recent developments in natural fibre composites and their mechanical performance, Compos. Part Appl. Sci. Manuf. 83 (2016) 98112. doi:10.1016/j.compositesa.2015.08.038.

[21] L. Zhang, M. Miao, Commingled natural fibre/polypropylene wrap spun yarns for structured thermoplastic composites, Compos. Sci. Technol. 70 (2010) 130-135. doi:https://doi.org/10.1016/j.compscitech.2009.09.016.

[22] F. Richard, D. Perreux, The safety-factor calibration of laminates for long-term applications: behavior model and reliability method, Compos. Sci. Technol. 61 (2001) 2087-2094. doi:10.1016/S0266-3538(01)00154-3.

[23] J. Lemaitre, J.L. Chaboche, Mechanics of solid materials, Cambridge University Press, 1994.

[24] B. Halphen, Q. Son Nguyen, Sur les matériaux standard généralisés, J. Mécanique. 14 (1975) 39-63.

[25] F. Richard, MIC2M Software: Modélisation et Identification du Comportement Mécanique des Matériaux / Modeling and Identification of the Mechanical Behavior of Materials, 2000. http://mic2m.univ-fcomte.fr.

[26] J.R. Dormand, P.J. Prince, A family of embedded Runge-Kutta formulae, J. Comput. Appl. Math. 6 (1980) 19-26. doi:10.1016/0771-050X(80)90013-3.

[27] F. Richard, Identification du comportement et évaluation de la fiabilité des composites stratifiés, Thèse de doctorat, Université de Franche-Comté, 1999.

[28] F. Richard, M. Villars, S. Thibaud, Viscoelastic modeling and quantitative experimental characterization of normal and osteoarthritic human articular cartilage using indentation, J. Mech. Behav. Biomed. Mater. 24 (2013) 41-52. doi:10.1016/j.jmbbm.2013.04.012.

[29] J.L. Chaboche, G. Rousselier, On the Plastic and Viscoplastic Constitutive Equations - Part I: Rules Developed With Internal Variable Concept, J. Press. Vessel Technol. 105 (1983) 153158. doi:10.1115/1.3264257.

[30] J.L. Chaboche, G. Rousselier, On the Plastic and Viscoplastic Constitutive Equations-Part II: Application of Internal Variable Concepts to the 316 Stainless Steel, J. Press. Vessel Technol. 105 (1983) 159-164. doi:10.1115/1.3264258.

[31] W. Prager, Recent Developments in the Mathematical Theory of Plasticity, J. Appl. Phys. 20 (1949) 235-241. doi:10.1063/1.1698348.

[32] C.O. Frederick, P.J. Armstrong, A mathematical representation of the multiaxial Bauschinger effect, Mater. High Temp. 24 (2007) 1-26. doi:10.1179/096034007X207589.

[33] T. Parenteau, E. Bertevas, G. Ausias, R. Stocek, Y. Grohens, P. Pilvin, Characterisation and micromechanical modelling of the elasto-viscoplastic behavior of thermoplastic elastomers, Mech. Mater. 71 (2014) 114-125. doi:10.1016/j.mechmat.2013.06.010.

[34] A. Bourmaud, C. Morvan, A. Bouali, V. Placet, P. Perré, C. Baley, Relationships between microfibrillar angle, mechanical properties and biochemical composition of flax fibers, Ind. Crops Prod. 44 (2013) 343-351. doi:10.1016/j.indcrop.2012.11.031.

[35] A. Del Masto, F. Trivaudey, V. Guicheret-Retel, V. Placet, L. Boubakar, Nonlinear tensile behaviour of elementary hemp fibres: a numerical investigation of the relationships between 3D geometry and tensile behaviour, J. Mater. Sci. 52 (2017) 6591-6610. doi:10.1007/s10853-017-0896-x.

[36] Y. Rabotnov, Creep Problems in Structural Members, North-Holland Publishing Company, 1969.

[37] L. Kachanov, Time of the rupture process under creep conditions, Izv Akad Nauk SSR Otd Tech Nauk. 8 (1958) 26-31.

[38] J. Lemaitre, R. Desmorat, Engineering damage mechanics ductile, creep, fatigue and brittle failures, Springer, Berlin; New York, 2005. 